\title{
$\mathrm{VHF} \mathrm{DSC}$ 에 의한 동해권 어업 $\mathrm{VMS}$ 의 통신운용 설계
}

\author{
최 조 천", 정 영 철", 김 정 욱", 최 명 수 ${ }^{* *}$, 이 성 로

\section{A Design on Radio-Communications Operation of the Fishery VMS by VHF DSC in the East Sea Area}

Jo-cheon Choi*, Young-cheol Jeong ${ }^{*}$, Jeong Uk Kim ${ }^{* *}$, Myeong Soo Choi ${ }^{* * *}$, Seong Ro Lee

요 약

5톤 이상의 어선에는 VHF(Very High Frequency) 대역의 DSC(Digital Selective Calling)가 어선법과 선박안전 법에 의무화되어 있다. 어선의 무선설비 관련 규정에는 안전운항을 확보하고 해양사고 발생시 신속하게 대응하기 위하여 선박의 소유자는 국토해양부장관의 고시에 따라 어선위치 자동발신 장치를 갖추도록 규정하고 있다. 따라 서 어업정보통신국은 2012년 동해를 시작으로 남해와 서해에 연차적으로 VHF 해안국을 설치하고, 웹기반으로 리 모트 콘트롤 및 모니터링에 의하여 DSC를 원격으로 운용하는 연안 VMS(Vessel Monitoring System) 구축사업이 추진중에 있다. 모든 어선의 VHF DSC는 GPS와 연동되며 DSC의 호출에 의하여 자동으로 위치정보를 중계소에 전송하게 된다. 본 논문에서는 동해권의 VHF DSC 해안국을 대상으로 통신해역 설정과 운용 그리고 등록선박의 항해에 따른 권역별 로밍서비스를 실현하는 항적추적과 RSSI (Received Signal Strength Indication) 기법을 병행 하는 알고리즘을 연구하였다.

Key Words : VHF DSC, VMS, GPS, RSSI

\section{ABSTRACT}

Fishing boats more than 5 tons is obliged to VHF DSC by Fishing Vessels Act and Vessel Safety Act. The owner of the fishing vessel is equipped to the automatic position reporting device in accordance with the Notice of the Minister of Land, Transport and Maritime Affairs to regulations, shall be ensure to navigations safety and in order to respond quickly in the event of maritime accidents on fishing vessels. East sea set up to start in 2012, which is now underway the annual install plain to the yellow sea and the south sea for VHF coast stations. It is web-based remote operation of DSC on the remote control and monitoring in Fishery Information Communication Station for the coastal VMS construction project. All fishing vessels is VHF DSC in conjunction with the GPS that location information transmitted to the coast station. automatically by the DSC call. This paper has been studied on the communications coverage set up and traffic operation for realization a roaming service by navigation route tracking and RSSI techniques in parallel algorithm refer to VHF DSC coast stations in east sea.

\footnotetext{
※ 이 논문은 2012년도 정부(교육과학기술부)의 재원으로 한국연구재단의 대학중점연구소 지원사업으로 수행된 연구임(2009-0093828)

※ 본 연구는 미래창조과학부 및 정보통신산업진흥원의 대학 IT연구센터 지원사업의 연구결과로 수행되었음(NIPA-2013-H0301-13-2005)

- 주저자 : 목포해양대학교 해양전자통신공학부, choijo@mmu.ackr, 정회원

교신저자 : 목포대학교 정보전자공학과, srlee@mokpo.ac.kr, 정회원

* 서울텔엔지니어링, seoultel1@nate.com

** 목포대학교 전자공학과, dbkimdb@ mokpo.ac.kr

*** 목포대학교 정보산업연구소, mschoi@mokpo.ac.kr, 정회원

논문번호 : KICS2013-01-034, 접수일자 : 2012년 1월 14일, 최종논문접수일자 : 2013년 3월 8일
} 


\section{I. 서 론}

DSC는 GMDSS(Global Maritime Distress and Safety System)의 운용에 있어서 매우 중요한 지원 시스템으로 기존의 해상통신 방식과 달리 디지털방 식의 선택적 호출응답으로 통신을 설정한다 ${ }^{[1]}$. DSC 의 호출 방식으로는 개별호출(Individual call), 그룹 호출(Group call), 해역호출(Geographical call), 일 괄호출(All ships call) 등이 있으며, 조난호출, 긴급 호출, 안전호출, 일반호출 등을 편집과 선택하여 호 출할 수 있다. 이미 우리나라에서도 GMDSS 대상 선박이 아닌 어선의 통신설비로 전파법령 및 어선 법령에서 2010년 12월에 어선설비기준이 개정되어 어선용 무선설비로 규정하고 있다. 5톤 이상의 어선 은 해상에서 조난시 자동으로 조난신호를 발사할 수 있는 VHF DSC 설비가 어선법과 선박안전법으 로 의무화되어 있으며, 선박안전법에서는 어선의 무 선설비 관련 규정 제 30 조에 “선박의 안전운항을 확 보하고 해양사고 발생시 신속한 대응을 위하여 국 토해양부령이 정하는 선박의 소유자는 국토해양부장 관이 정하여 고시하는 기준에 따라 선박의 위치를 자동으로 발신하는 장치(선박위치발신장치)를 갖추 고 이를 작동하여야 한다."로 되어 있다. 또한, 어선 법 제 5 조의 2 에 "어선의 안전운항을 확보하기 위하 여 농림수산식품부령으로 정하는 어선의 소유자는 농림수산식품부장관이 정하는 기준에 따라 어선의 위치를 자동으로 발신하는 장치(어선위치발신장치) 를 갖추고 이를 작동하여야 한다." 로 되어 있다.

현재로서 소형 어선에서 어선법으로 지정하는 어 선위치발신 장치를 해결할 수 있는 방법은 VHF DSC가 유일하며, GPS(Global Positioning System) 와 연동되어 $\mathrm{DSC}$ 의 호출에 자동응답 기능으로 위 치정보를 제공하는 육해상간의 시스템 구축이 필요 하다. 이에 어업정보통신국은 2011년 속초어업정보 통신국의 $\mathrm{VHF} \mathrm{DSC}$ 시범사업의 성공에 이어 본격 적으로 전국적인 $\mathrm{VHF} \mathrm{DSC}$ 구축사업을 2012년부 터 추진중에 있다. 본 논문에서는 동해권의 10 개소 VHF DSC 해안국을 대상으로 해상의 통신군 설정 과 통신운용 그리고 등록선박의 항해에 따른 권역 별 $\mathrm{DB}$ 구축과 로밍서비스를 실현하기 위한 항적추 적과 RSSI(Received Signal Strength Indication) 기 법을 병행하는 알고리즘에 대하여 연구하였다 ${ }^{[2]}$.

\section{VHF DSC의 기능과 운용}

\section{1. $\mathrm{VHF} \mathrm{DSC}$ 의 기능}

VHF DSC의 기술적 특성은 ITU-R M. 493에 그리 고 조난통신을 비롯한 모든 종류의 통신운용에 대한 절차는 ITU-R M. 541에 권고되어 있다 ${ }^{[3,4]}$.

표 1. VHF DSC의 등급

Table 1. Class of VHF DSC

\begin{tabular}{|c|c|c|}
\hline Division & Class-A type & Class-D type \\
\hline Function & $\begin{array}{l}\text { - DSC call } \\
- \text { Auto voice calling }\end{array}$ & DSC call \\
\hline DSC Ant. & Necessary & No useful \\
\hline Operation & GMDSS ship & Non-GMDSS ship \\
\hline
\end{tabular}

VHF DSC의 종류에는 크게 두 가지가 있으며, 국 제항해 여객선 및 총톤수 300 톤 이상 국제항해 화물 선에 해당되는 GMDSS 선박에 적용되는 class-A 타 입과 그 외의 선박인 비 GMDSS 선박에 적용되는 class-D 타입으로 나누어져 있다. 따라서 어선에는 class-D 타입의 VHF $\mathrm{DSC}$ 가 설치되며, class-A와 class-D에 대한 주요 성능비교는 표 1과 같다. Class$\mathrm{D}$ 타입의 경우 전용 안테나가 없이 $\mathrm{VHF}$ 송수신 안테 나를 겸용으로 사용하기 때문에 음성송신 중에는 $\mathrm{DSC}$ 신호를 수신할 수 없다.

DSC 호출응답은 무선전화 통신과 달리 약 0.6초의 단시간에 전송이 종료된다. 또한 VHF DSC 호출응답 채널은 Ch.70 (156.525M/z) 하나로 지정되어 있기 때 문에 통신국별로 주파수를 다르게 지정할 수 없다.

$\mathrm{DSC}$ 의 통신권은 $\mathrm{VHF}$ 무선전화 통신권과 동일하 기 때문에 VHF DSC 통신권 구성 방안은 VHF 무선 전화 통신권 구성방안과 동일하게 적용된다.

\section{2. 동해권 $\mathrm{VHF} \mathrm{DSC}$ 의 운용}

그림 1은 동해권 VHF DSC 위치자동발신시스템을 구축하기 위한 네트워크의 개요도이다. 네트워크는 웹 기반의 VoIP 방식으로 구성되며, 서울에 종합관제실 1 국, 속초와 포항에 운영국 2 국, 주문진, 동해, 후포, 울릉, 울산에 모니터국 5국 그리고 선박통신을 운용되 는 10 개의 해안국이 설치된다. 


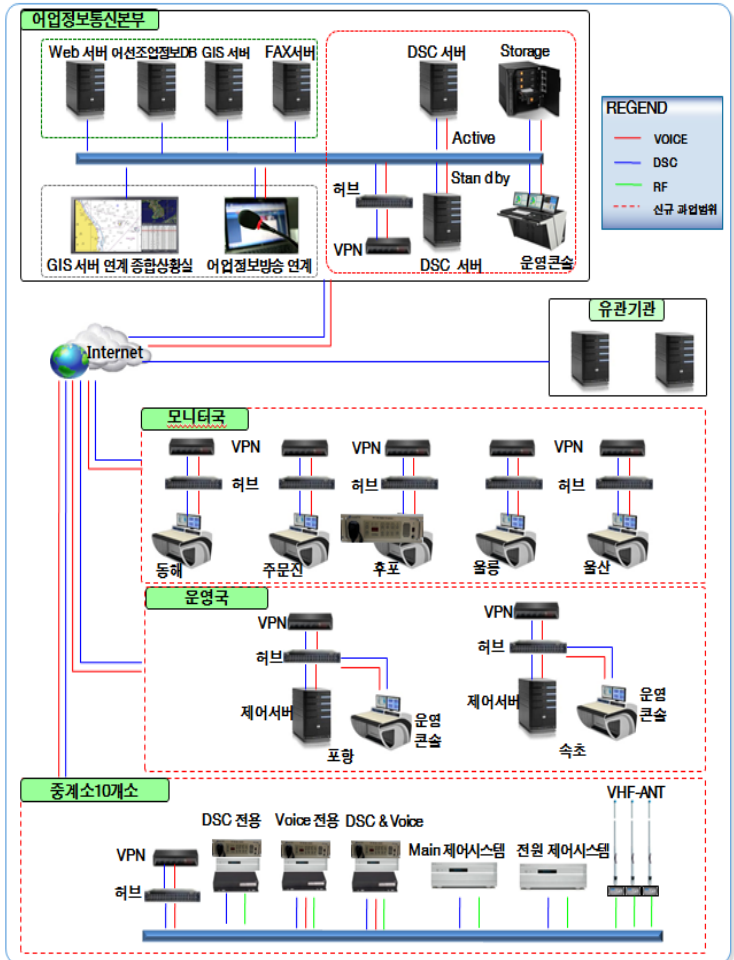

그림 1. 동해권 VHF DSC의 VMS 네트워크

Fig. 1. VMS network of VHF DSC in East sea

해상에서의 $\mathrm{VHF}$ 통신은 송-수신소 각각의 안 테나 높이에 의하여 가시거리 통신으로 규정할 수 있다. 광학적 가시거리의 계산식은 지구등가 반경계 수를 $\mathrm{K}=4 / 3$ 으로 가정한 경우 다음의 식과 같다.

$$
D=4.11(\sqrt{h 1}+\sqrt{h 2})
$$

여기서, $\mathrm{D}$ 는 가시거리를 나타내고, $\mathrm{h} 1, \mathrm{~h} 2$ 는 각각 송신측 유효안테나 높이 $(\mathrm{m})$ 와 수신측 유효안테나 높 이(m)를 나타낸다.

VHF 전파의 통달거리는 식 (1)을 기본으로 예측하 며, 안테나의 높이와 GIS 정보를 활용하여 커버리지 를 시뮬레이션하는 도구를 사용하여 전파환경을 예측 하였다.

그림 3 에서 10 개의 해안국은 모두 동일한 $\mathrm{VHF}$ Ch.70을 운용하므로 인접한 국끼리 동일시간에 데이 터를 전송하면 신호가 충돌되어 서로의 데이터는 신 호는 훼손되어 전송이 불가능하게 된다. 그러므로 커 버리지 내에서 인접국간 전파가 겹치지 않도록 운용 시간을 배치하여야 한다. 그림에서 해안국을 5 개의 그 룹으로 나누고, 인접국과 호출운용이 겹치지 않도록 호출시간을 할당하여 배치한 내용을 나타내고 있다 ${ }^{[2]}$.

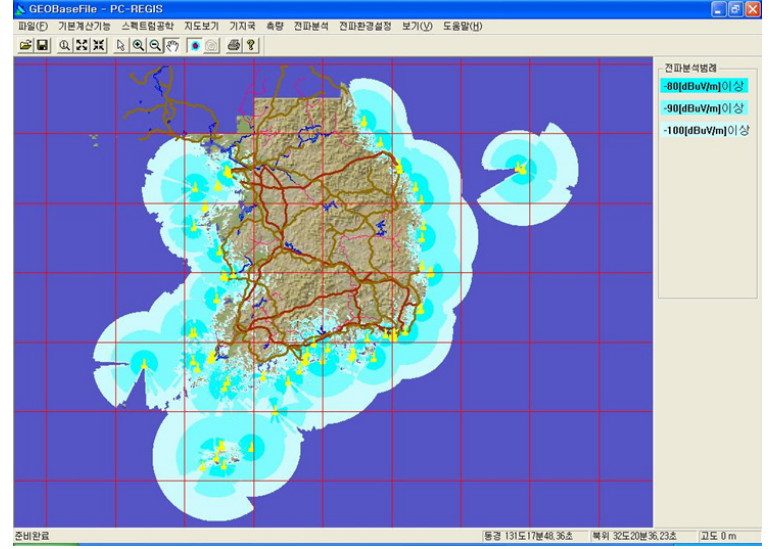

그림 2. VHF 커버리지의 시뮬레이션

Fig. 2. Simulation of VHF coverage

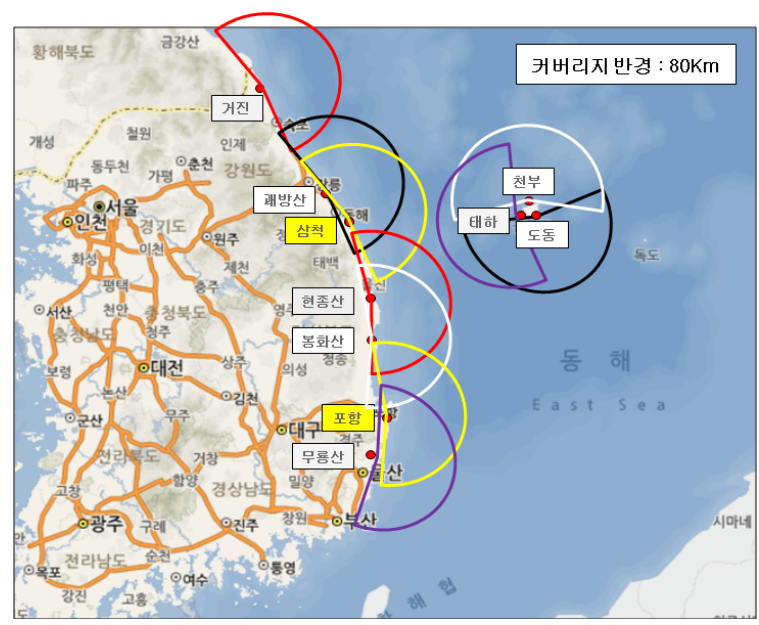

\begin{tabular}{|c|c|c|c|c|}
\hline 그룹명 & 구문 & $\begin{array}{l}\text { 운용시간 } \\
\text { (분) }\end{array}$ & 운용중계소 & $\begin{array}{l}\text { 동시 문용가능 } \\
\text { 중계소 }\end{array}$ \\
\hline A & & $00-10$ & 거진, 현종산 & 무룡산, 천부 \\
\hline B & & $10-20$ & 괘방산, 도동 & 포함 \\
\hline c & & $20-30$ & 무룡산, 태하 & 거진 \\
\hline D & & $30-40$ & 봉화산, 천부 & 괘방산 \\
\hline E & & $40-50$ & 삼쳑, 포함 & 거진, 도동 \\
\hline \multicolumn{2}{|c|}{$\mathrm{F}$} & $50-60$ & 안전조업상황실 설정 & 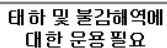 \\
\hline
\end{tabular}

그림 3. 시뮬레이션에 의한 통신권의 설계

Fig. 3 Design of station's coverage by Simulation

\section{3. 통신시퀀스}

$\mathrm{DSC}$ 의 위치보고 통신프레임은 그림 4 와 같이 $260 \mathrm{bit}$ 로 구성되며, VHF DSC의 전송속도는 $1,200 \mathrm{bit}$ 이므로 프레임의 전송시간을 계산하면 0.21667 초가 되고, 호출과 응답에서 지연시간을 고려하지 않을 경 우에는 약 0.44 초가 소요된다.

\begin{tabular}{|c|c|c|c|c|c|c|c|c|c|c|}
\hline $\begin{array}{c}\text { Dot 신호 } \\
\text { 20bit }\end{array}$ & $\begin{array}{c}\text { 동기신호 } \\
\text { 20bit }\end{array}$ & $\begin{array}{c}\text { Format } \\
\text { 10bit }\end{array}$ & $\begin{array}{c}\text { Address } \\
\text { 50bit }\end{array}$ & $\begin{array}{c}\text { Category } \\
\text { 10bit }\end{array}$ & $\begin{array}{c}\text { 자국식별 } \\
\text { 50bit }\end{array}$ & $\begin{array}{c}\text { 메시지 1 } \\
\text { 20bit }\end{array}$ & $\begin{array}{c}\text { 메시지 2 } \\
\text { 30bit }\end{array}$ & $\begin{array}{c}\text { 메시지 3 } 3 \\
\text { 30bit }\end{array}$ & $\begin{array}{c}\text { 종료코드 } \\
10 b i t\end{array}$ & $\begin{array}{c}\mathrm{ECC} \\
10 \mathrm{bit}\end{array}$ \\
\hline
\end{tabular}

그림 4. 통신프레임의 구성

Fig. 4. Construction of communication frame 
$\mathrm{DSC}$ 자동응답 모드에서 해안국이 선박국의 호출절 차와 선박국의 응답절차에 대한 통신시퀜스는 그림-5 와 같으며, 통신프로토콜에 표기된 문자의 내용은 표 -3과 같다. a)의 경우에는 즉시 응답이 가능한 경우로 선박에서 $\mathrm{DSC}$ 의 송수절환에 의하여 위치정보로 응답 하게 되고, b)의 경우는 수신된 정보의 에러 또는 Ch.70 전파의 사용중으로 응답을 할 수 없을 때이며, 어선의 class-D 형 DSC는 해안국의 재호출을 대기하 는 상태로 된다 ${ }^{[5]}$.
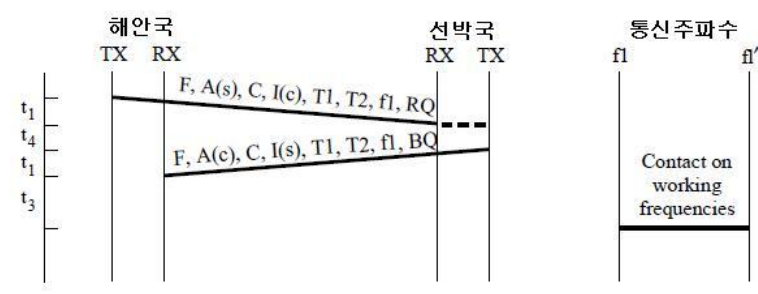

a) 응답 가능 경우
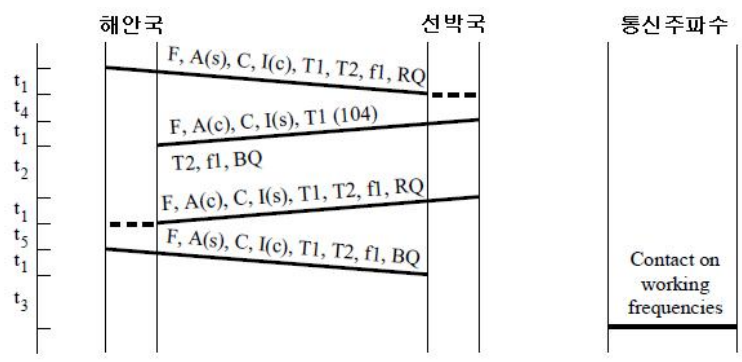

b) 응답 불가능 경우 (통신중)

그림 5. 호출응답 시퀜스

Fig. 5. Sequence of calling \& response

표 2. 통신프로토콜 구성

Table 2. Construction of communication protocol

\begin{tabular}{|c|l|}
\hline Character & \multicolumn{1}{|c|}{ Content } \\
\hline $\mathrm{t}_{1}$ & DSC calling time \\
\hline $\mathrm{t}_{2}$ & DSC calling reception knowledge time \\
\hline $\mathrm{t}_{3}$ & Calling time in working frequency \\
\hline $\mathrm{t}_{4}$ & $\begin{array}{l}\text { Responding time in auto respond mode } \\
\text { (three second in VHF DSC) }\end{array}$ \\
\hline $\mathrm{t}_{5}$ & Respond setting time \\
\hline $\mathrm{F}$ & Message format (Position Request) \\
\hline $\mathrm{A}$ & MMSI of called station \\
\hline $\mathrm{I}$ & MMSI of calling station \\
\hline $\mathrm{C}$ & Category (ex: Safety, Routine etc.) \\
\hline $\mathrm{T} 1$ & Tele-command 1 \\
\hline $\mathrm{T} 2$ & Tele-command 2 \\
\hline $\mathrm{f} 1, \mathrm{f} 2$ & Working frequency \\
\hline $\mathrm{RQ}, \mathrm{BQ}$ & Finished signal \\
\hline
\end{tabular}

ITU-R M. 541의 규정에 따라 선박이 자동으로 $\mathrm{DSC}$ 의 운용을 지원하는 장치를 탑재하면, 선박국은 자동적으로 종료신호 "BQ"를 가진 확인을 송신해야 한다. 이러한 확인 시퀀스의 전송시작은 완전한 호출 시퀀스의 수신이후, 3 초 이내에 이루어져야 한다. 그 리고 해안국의 통화중이 수신된다면 초기 호출로부터 15 분의 주기 이내에 호출한 해안국의 재호출을 수신 할 수 있어야 한다. 이외에도 해상 VHF 디지털통신의 향상된 성능을 적용할 수도 있으나, 본 연구의 범위는 $\mathrm{DSC}$ 의 기능 및 class-D의 성능으로 한정된다 ${ }^{[6,7]}$. 그 림 6은 해안국의 커버리지로 구분하여 해역을 분할한 것으로 해상통신에서 통신권에 해당되며, 직사각형 해 역은 $75 \times 150 \mathrm{~km}^{2}$ 를 기준으로 설정하였고, 강원도와 울 릉도 해안국간의 커버리지에서 전파가 겹치지 않도록 그룹을 설계하여 운용시간을 배치하여야 한다. $\mathrm{VHF}$ $\mathrm{DSC}$ 에 의한 어선의 자동위치발신 시스템은 해안국이 모두 동일한 채널 70을 사용하며, 부근의 모든 해안국 은 동시에 선박의 위치정보를 수신하게 되므로 그중 에서 수신신호가 가장 양호한 해안국을 선별하여 통 신을 행하는 RSSI 방식을 적용할 수 있다.

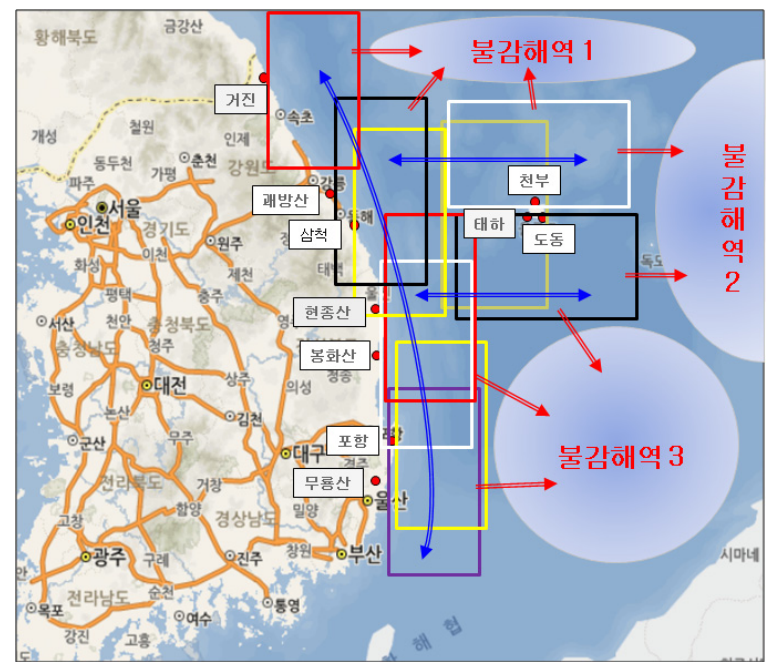

그림 6. 통신해역과 항로추적

Fig. 6. Traffic area \& tracking of navigation route

그림 7은 RSSI를 구현하기 위한 설계도로 해안국 중에서 가장 양호한 수신신호는 해안국 $\mathrm{C}$ 의 전파이므 로 해당 선박은 해안국 $\mathrm{C}$ 해역의 항해선박 $\mathrm{DB}$ 에 등 록되어 통신해역으로 설정된다. 


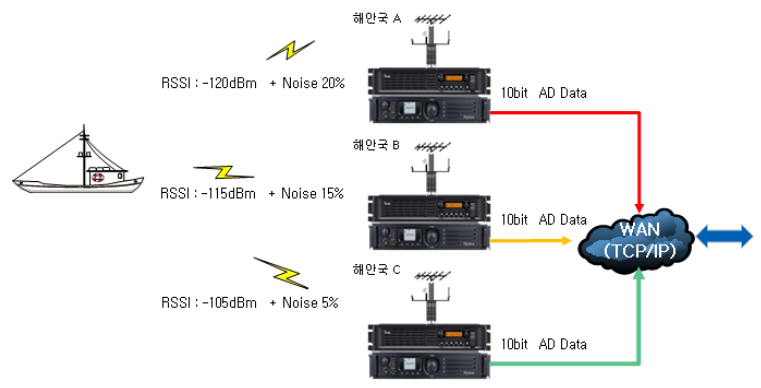

선박이 해안으로부터 멀어져서 VHF 통신의 불감 해역으로 진입하게 되면 해당선박은 자동으로 이탈선 박 $\mathrm{DB}$ 에 등록이 되고, 이 선박들은 $\mathrm{SSB}$ 의 호출에 의 하여 위치정보를 얻어야 한다.

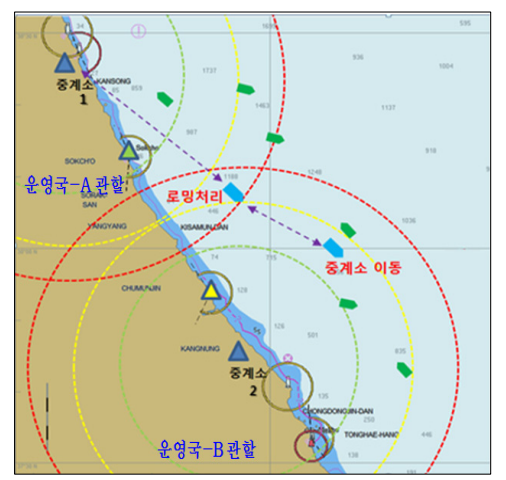

그림 9. RSSI 비교에 의한 로밍

Fig. 9. Roaming by RSSI comparer 태의 특성그래프를 나타내므로 RSSI의 적용에 매우 적합하다 ${ }^{[10]}$.
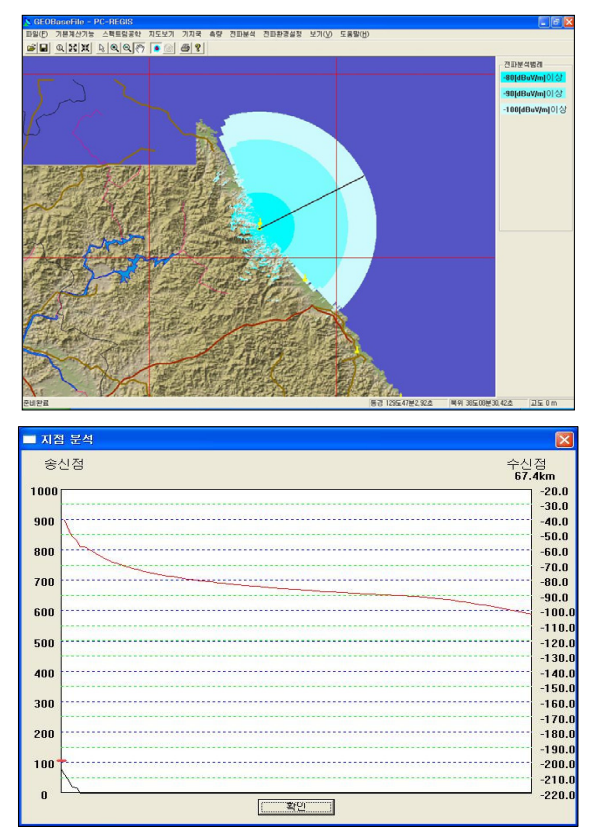

그림 8. 동해안의 $\mathrm{VHF}$ 전파환경

Fig. 8. VHF radio environment in East sea

\section{III. 알고리즘의 설계}

그림-9는 선박의 이동경로에 따라 해안국을 로밍하 는 절차를 보인 것으로 RSSI의 비교에 따라 수신전계 가 가장 양호한 해안국의 선박 $\mathrm{DB}$ 에 자동으로 등록 되며, 그림 9와 같이 인접하는 해안국과 RSSI에 의한 거리정보에서 2 개의 원을 도시하므로써 교점으로 선 박의 위치를 추적할 수 있다. 

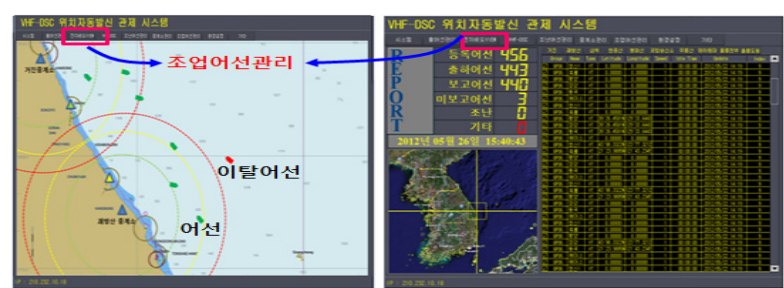

그림 11. 어업 VMS 화면

Fig. 11. Screen of fishery VMS

그림 11은 조합 알고리즘에 의하여 설계된 어업 VMS의 화면을 보인 것으로 전자해도는 국립해양조 사원의 S-57 규격을 사용하였다. 자유로운 전자해도 의 표출과 함께 호출선박, 해역별 선박, $\mathrm{VHF}$ 통신권 이탈선박 등의 $\mathrm{DB}$ 를 동시에 관리할 수 있도록 설계 하였다.

\section{IV. 결 론}

국내 연안어선의 해상안전과 해난에 신속하게 대응 하는 방안으로 자동위치 발신장치를 의무화하였으며, 간단하게 이러한 기능을 만족하는 VHF DSC를 의무 설비로 규정하였다. 특히, 어업용 $\mathrm{VMS}$ 와 연동되는 감시레이더에 의하여 연안에서 조업하는 타국의 어선 및 의아 선박에 대한 식별을 용이하게 하려는 목적도 포함하고 있다.

현재 어업정보통신국은 하루에 2회 정도 음성호출 에 의하여 어선들을 위치보고를 접수하고 있으나, $\mathrm{VHF} \mathrm{DSC}$ 에 의한 자동위치보고 시스템이 완성되면 표-2에 의하여 VHF 통신권에서는 1시간에 1회이상의 위치보고를 접수할 수 있다. 다만, VHF 통신권을 이 탈하여 불감해역으로 항해하는 어선에 대해서는 기존 의 SSB로 호출하여 위치보고를 접수하게 되며, 이탈 선박이 다시 VHF DSC의 호출에 응답하는 경우에는 $\mathrm{RSSI}$ 에 의하여 해당 해역의 항해선박으로 $\mathrm{DB}$ 에 갱신 하게 된다. 결론으로 어선의 항해가 가장 많은 연안해 역에 대하여 VHF DSC의 운용에 의한 자동위치보고 시스템은 어업 $\mathrm{VMS}$ 의 기능을 신속하고 정확하도록 상향시키는 효과를 얻을 수 있다.

\section{References}

[1] IMO, "Performance standards ship borne VHF radio installations capable of voice communication and digital selective calling," IMO Resolution A.803-19, Nov. 1995.

[2] J. C. Choi, "A study on the improvement of frequencies and systems for efficient operations in fisheries information communications," Nat. Federation Fisheries Corperatives, pp. 100-103, Dec. 2012.

[3] ITU-R, "Digital selective calling system for use in the maritime mobile service," ITU-R Recommendation M.493-13, Oct. 2009.

[4] ITU-R, "Operational procedures for the use of digital selective calling equipment in the maritime mobile service," ITU-R Recommendation M.541-9, May 2004.

[5] TTA, "The Test of Digital Selective Calling Equipments," TTA Standard TTAK.KO-06.0078/R1, Dec. 2011.

[6] ITU-R, "International maritime $\mathrm{VHF}$ radiotelephone system with automatic facilities based on DSC signalling format," ITU-R Recommendation M.689-3, Mar. 2012.

[7] ITU-R, "Optional expansion of the digital selective calling system for use in the maritime mobile service," ITU-R Recommendation M.821-1, Feb. 1997.

[8] B. O. Kim, "A study on the corresponding strategies in accordance with establishment of obligatory on VHF, fishery information communications," Nat. Federation Fisheries Corperatives, pp. 171-174, Oct. 2010.

[9] Y. C. Jung, Y. M. Cha, G. U. Kim, J. C. Choi, "Standardized trend for digital communications of maritime VHF band," in Proc. KICS Int. Conf. pp. 72-74, Gwangju, Korea, May, 2011.

[10] B. E. Nam, "A Study of mobile node forecasts the location area by using the differentiated ratio of RSSI," M.S. thesis, Dept. Computer Sci. Eng., The Graduate School Inform. Sci. Kyung Hee University, Korea, pp. 21-25, 2006. 
최 조 천 (Jo-cheon Choi)

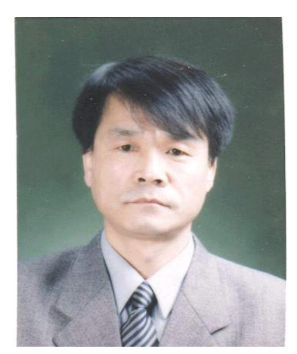

1986년 2월 서울산업대학교 전자공학과 공학사

1990년 2월 조선대학교 컴퓨 터공학과 공학석사

1998년 2월 한국해양대학교 전자통신공학과 공학박사 1989년 현재 목포해양대학교 해양전자통신공학부 교수 <관심분야> 해양전자통신, 계측제어

정 영 철 (Yeong-cheol Jeong)

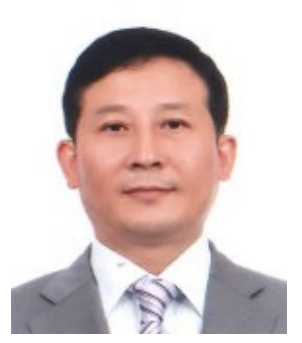

1983년 2월 목포해양대학교 통신학과 공학사

2004년 8월 경희대학교 정보통 신망관리학과 공학석사

2013년 1월 목포해양대학교 해양 전자통신공학과 공학박사

현재 서울텔엔지니어링 대표 <관심분야> 해상통신, 네트워크

\section{김 정 욱 (Jeong $\mathrm{Uk} \mathrm{Kim)}$}

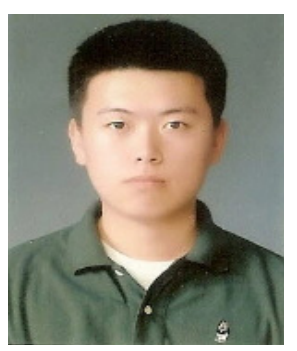

2013년 2월 목포대학교 정보전 자공학과 공학사

2013년 3월 현재 목포대학교 전자공학과 석사과정 <관심분야> 디지털통신시스템, 이동 및 위성통신시스템, $\mathrm{USN} /$ 텔레매틱스응용분야,

\section{최 명 수 (Myeong Soo Choi)}

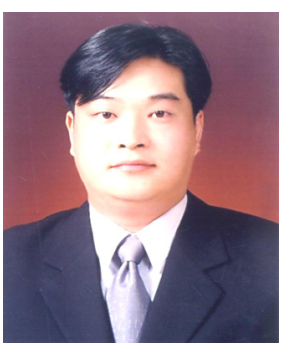

2000년 2월 목포대학교 전자 공학과 공학사

2002년 2월 목포대학교 전자 공학과 공학석사

2009년 2월 목포대학교 전자 공학과 공학박사

2009년 3월 목포대학교 해양 텔레매틱스기술개발센터 박사후연구원

2009년 12월 현재 목포대학교 정보산업연구소 연 구전임교수

<관심분야> 디지털통신시스템, USN, 배열신호처리, 임베디드시스템

\section{이 성 로 (Seong Ro Lee)}

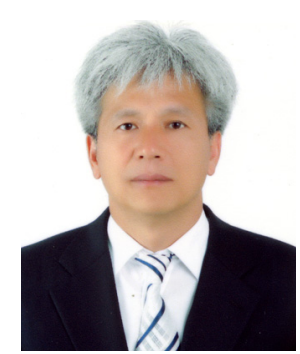

1987년 2월 고려대학교 전자 공학과 공학사

1990년 2월 한국과학기술원 전기및전자공학과 공학석사 1996년 8월 한국과학기술원 전기및전자공학과 공학박사 1997년 9월 현재 목포대학교 공과대학 정보전자공학과 교수

<관심분야> 디지털통신시스템, 이동 및 위성통신시 스템, USN/텔레매틱스응용분야, 임베디드시스템

임베디드시스템 